\title{
Foreign Language Enjoyment and Classroom Anxiety of Chinese EFL Learners With Intermediate and Low English Proficiency
}

\author{
Huina $\mathrm{Su}$ \\ University of Macau, Macao, China; \\ Hainan University, Hainan, China
}

\begin{abstract}
Driven by Positive Psychology, research on emotions in second language acquisition has moved from The Anxiety-Prevailing Phase to Positive and Negative Emotions Phase (Dewaele \& Li, 2020). A growing number of scholars begin to study learners' emotions from a more holistic perspective. The present study investigated the levels and sources of foreign language enjoyment (FLE) and foreign language classroom anxiety (FLCA) of 231 Chinese EFL undergraduates with intermediate and low English proficiency. The study found moderate levels of both FLE and FLCA among participants. However, the level of FLE was much lower than the international and domestic samples, while the level of FLCA showed the opposite pattern. There was no significant gender difference emerged for FLE, while female participants reported more FLCA than their male counterparts. Moreover, no significant difference was found in the levels of both FLE and FLCA between intermediate and low English proficiency students. Qualitative data analysis confirmed that FLE was closely related to teacher factors while FLCA was more related to learners themselves. Based on these findings, pedagogical implications were provided for EFL teaching in China.
\end{abstract}

Index Terms-Positive Psychology, foreign language enjoyment, foreign language classroom anxiety, intermediate and low English proficiency, Chinese EFL undergraduates

\section{INTRODUCTION}

For a long time, scholars have been keen to explore the impact of cognitive factors on second language acquisition (SLA), but seldom paid attention to emotion which was regarded as an irrational factor in SLA research. Although the vital role of emotions in learning was later recognized (Scovel, 1978; Krashen, 1985), the focus of research in this field has always been on problematic, distressing aspects, especially on learner anxiety. In 2012, the introduction of the concept of Positive Psychology (PP) stimulated a positive psychology movement in applied linguistics (MacIntyre \& Gregersen, 2012). In the past few years, researchers in the SLA field have gradually expanded their concentration upon anxiety in the past to a study of both positive and negative emotions in the classroom setting, the complexity and dynamic interaction between emotions as well as learners' well-being (Dewaele \& Li, 2020).

Enjoyment and anxiety are two common emotions experienced by foreign language (FL) learners. Since Dewaele and MacIntyre (2014) first explored the relationship between foreign language enjoyment (FLE) and foreign language classroom anxiety (FLCA), the two emotions have always been examined together in different learning settings. As two different dimensions, studies have revealed that the increase of one emotion was not simply followed by the decrease of the other (Dewaele \& MacIntyre, 2014; Boudreau, MacIntyre, \& Dewaele, 2018). Hence, it was suggested that both positive and negative emotions should be investigated together in the same study (Dewaele \& MacIntyre, 2014; Dewaele, Witney, Saito, \& Dewaele, 2018).

To date, A few studies have explored FLE and FLCA of Chinese EFL learners in high school or higher education contexts (e.g., Jiang \& Dewaele, 2019; Li, 2020; Li, Huang, \& Li, 2020). However, no such study has targeted at intermediate and low English proficiency learners in China. China is currently the country with the largest number of English learners in the world, among which intermediate and low English proficiency learners account for a large proportion. Such a research is worthwhile because it can provide a better understanding of L2 emotions experienced by Chinese EFL learners and also shed light on improving foreign language education in China. With a mixed method, the present study seeks to examine the levels and sources of both FLE and FLCA of Chinese EFL learners with intermediate and low English proficiency.

\section{LITERATURE REVIEW}

\section{A. Foreign Language Anxiety}

As a psychological construct, anxiety is defined as "a vague fear that is only indirectly associated with an object and an emotional state generated through the arousal of the limbic system, the primitive, subcortical 'chasis' of the cerebrum" (Scovel, 1978, p.134). Spielberger (1983) referred to anxiety more specifically as "subjective feelings of 
tension, apprehension, nervousness, and worry, and by activation or arousal of the autonomic nervous system" (p.1). As a multi-faceted concept, several types of anxiety have been differentiated by psychologists, such as trait anxiety, state anxiety, situation-specific anxiety.

Categorized as a type of situation-specific anxiety, foreign language anxiety (FL anxiety) is a complex and multidimensional phenomenon, referring to "a distinct complex of self-perceptions, beliefs, feelings, and behaviors related to classroom language learning arising from the uniqueness of the language learning process" (Horwitz, Horwitz, \& Cope, 1986, p.128). MacIntyre and Gardner (1994a) defined it as "the feeling of tension and apprehension specifically associated with second language contexts, including speaking, listening, and learning” (p.284). Horwitz, Horwitz, and Cope (1986) identified three varieties of FL anxiety: communication apprehension, test anxiety, and fear of negative evaluation.

Anxiety might interfere with the process of learning and acquiring a language (Krashen, 1982). Horwitz (2000) believed that the interference of anxiety on learning and performance is one of the most commonly accepted phenomena in psychology and education. For decades, the negative emotion of anxiety has attracted much attention and has become the most studied emotion in the field of SLA. While some studies confirmed anxiety as a crucial affective barrier in language learning achievement (e.g., Aida, 1994; MacIntyre \& Gardner, 1994a, 1994b), some revealed the effects of facilitative anxiety (e.g., Chastain, 1975; Bailey, 1983). In short, the relationship between FL anxiety and FL learning is complex. Although the earlier studies have yielded some ambiguous and contradictory results in terms of the relationship between anxiety and FL performance, it is generally admitted that FL anxiety negatively affects FL achievement (Horwitz, 2010; Liu \& Jackson, 2008; Dewaele \& Alfawzan, 2018).

Anxiety may not only have a destructive effect on learners' behavior but also an interference with interpersonal communication, cognition and learning (Gregersen \& Horwitz, 2002), research probing into its impact on FL learning has always been crucial. Studies on identifying the sources of anxiety have emerged greatly since anxiety came into the sight of SLA researchers. FL anxiety was found to be bound up with some of learners' personality traits like competitiveness, perfectionism, and trait anxiety (e.g., Bailey, 1983; Gregersen \& Horwitz, 2002; Horwitz, 1986; Chiang, 2010). Classroom environment was also identified as a potential anxiety contributor (Cohen \& Norst, 1989; Piechurska-Kuciel, 2011). In addition, FL anxiety may also have a correlation with some societal variables like family's social status (Dewaele, 2002). As FL anxiety is the result of a combination of internal and external factors, it's of great necessity to continue conducting researches that compare the effects of different variables on FL anxiety to enhance our understanding towards this negative emotion of FL learning.

\section{B. Foreign Language Enjoyment}

The concept of PP was introduced into SLA by MacIntyre and Gregersen (2012), which stimulated a positive emotional movement in the field of SLA research. PP is a rapidly developing branch of psychology. It strives to develop tools to build positive emotions, greater engagement, and an appreciation of meaning in life and its activities (Seligman, 2006; MacIntyre \& Mercer, 2014). Among positive emotions, enjoyment is a prevalent emotion experienced by learners in learning (Elahi Shirvan \& Taherian, 2018). Seligman and Csikszentmihalyi (2000) differentiate "pleasure" from "enjoyment". Dewaele and MacIntyre (2016) further clarified that "enjoyment" is not simply an agreeable feeling as "pleasure". It can be defined as a complex emotion which occurred "when people not only meet their needs, but exceed them to accomplish something new or even unexpected" (p. 217). The role of enjoyment was grounded on positive psychologist Barbara Fredrickson's Broaden-and-Build Theory (2001, 2003). Fredrickson (2003) proposed that certain discrete positive emotions, such as joy, interest, contentment, pride, and love can broaden people's momentary thought-action repertoires and build their enduring personal resources, ranging from physical and intellectual resources to social and psychological resources.

Currently, FLE is the most concerned positive emotion in SLA field (Dewaele \& Li, 2018). Dewaele and MacIntyre (2014) developed a 21-item Foreign Language Enjoyment Scale (FLE Scale) to reflect learners' positive emotions towards learning experiences, peers and teachers. They gathered data from 1746 participants from all over the world and found that FLE and FLCA were two relatively independent emotions with a moderately negative correlation. Since then, many studies have shown that these two emotions were not only closely correlated with learners' FL performance (e.g., Dewaele \& Alfawzan, 2018; Li, Dewaele, \& Jiang, 2019), but also affected by various individual factors (e.g., gender, personality, proficiency level) and social factors (e.g., teacher, classroom environment, cultural background) (Dewaele \& MacIntyre, 2014; Dewaele, Witney, Saito, \& Dewaele, 2018; Jiang \& Dewaele, 2019).

Compared with studies abroad, PP has developed slowly in China and is still in its infancy (Jiang \& Li, 2017). Studies on the FLE of Chinese students have begun to emerge in recent years. With a mixed-method approach, Li, Jiang, and Dewaele (2018) developed a Chinese Version of the Foreign Language Enjoyment Scale and investigated the levels and sources of FLE of Chinese high school students. A 3-factor structure of FLE, namely FLE-Private, FLE-Teacher and FLE-Atmosphere, was identified after a series of exploratory and confirmatory factor analyses. The results of descriptive analyses showed that the participants scored highest on the dimension of FLE-Teacher, followed by FLE-Private and FLE-Atmosphere. The study also revealed that FLE experienced by Chinese EFL learners was mainly related to the teachers, the learner and the classroom atmosphere (controlled by the teacher).

Jin and Zhang (2018) investigated the dimensions of foreign language classroom enjoyment and their effect on FL achievement. Participants were 320 Chinese senior high school students. They found a 3-factor solution for the adapted 
FLE scale: Enjoyment of Teacher Support, Enjoyment of Student Support, and Enjoyment of FL Learning. Further analysis revealed that FLE had a direct effect on EFL learners' FL achievement.

In a qualitative study, Jiang (2020) examined the teacher-related factors in 646 Chinese college students' FLE with the focused essay technique. They found that there were mainly five categories of teacher-related factors, which were classroom activity organization, teacher characteristics, teacher skills, teaching content, and teacher support. The types of teacher-related factors that affected students' FLE had different proportions, and the ways in which they affected FLE were also different.

What emerged from the literature review is that although a few studies have investigated foreign language (classroom) enjoyment of Chinese EFL learners, the examination of both FLE and FLCA in the same study is still greatly needed. Besides, no study has yet specifically investigated the classroom emotions of intermediate and low proficiency Chinese EFL learners. Considering the large proportion of this learner group in EFL learners in China, the study of their anxiety and enjoyment in the FL classroom is of great necessity.

\section{RESEARCH QUESTIONS}

The following questions were addressed in this study.

RQ1: What are the levels of FLE and FLCA of Chinese EFL learners with intermediate and low English proficiency?

RQ2: Are there any gender differences in FLE and FLCA among participants?

RQ3: Are there any significant differences in FLE and FLCA between the intermediate and low English proficiency students?

RQ4: What are the sources of FLE and FLCA for Chinese EFL learners with intermediate and low English proficiency?

\section{Methodology}

\section{A. Participants}

A total of 231 second-year non-English major undergraduates in a Chinese university, including 115 females and 116 males, participated in the research. Their average age was 19.95 years old $(S D=0.747)$. They came from 4 intact College English classes (Class A, B, C, and D) randomly chosen. College English courses are compulsory courses for non-English major freshmen and sophomores in this university. Each semester, students are grouped and placed in English classes of different levels based on the results of their last College English final exam (Total score: 100 points). Class A and B were targeted at intermediate English proficiency students, with an average score of 67.92 (see Table 1). Class C and D were for students with low English proficiency, the average score was 53.03. In this study, Class A and B constituted the intermediate level group while Class $\mathrm{C}$ and $\mathrm{D}$ was the low level group. Independent $t$-tests revealed a significant difference in the average scores of the two groups $(p=.000)$.

TABLE I

BACKGROUND INFORMATION OF PARTICIPANTS

\begin{tabular}{cccccc}
\hline Class & $N$ & Female & Male & Average age $(S D)$ & Average score of English final \\
\hline A & 60 & 34 & 26 & $19.87(.791)$ & 67.23 \\
B & 60 & 36 & 24 & $19.95(.811)$ & 68.60 \\
C & 50 & 16 & 34 & $20.04(.727)$ & 55.22 \\
D & 61 & 29 & 32 & $19.97(.657)$ & 50.84 \\
In total & 231 & 115 & 116 & $19.95(.747)$ & 60.47 \\
\hline
\end{tabular}

\section{B. Instruments}

\section{Composite Questionnaire}

The composite questionnaire consisted of two sections. The first section was to collect participants' sociobiographical information (such as gender, age, class, etc.). The second section had 19 items in total, which included the Foreign Language Classroom Anxiety Scale and the Foreign Language Enjoyment Scale (revised Chinese version) (see Appendix).

a. Foreign Language Classroom Anxiety Scale

Dewaele and MacIntyre (2014) extracted 8 items from the 33-item Foreign Language Classroom Anxiety Scale (FLCAS) devised by Horwitz, Horwitz, and Cope (1986). It retained the reliability and validity of the original scale and have been verified and used in several studies (e.g., Dewaele \& Alfawzan, 2018; Jiang \& Dewaele, 2019). This study adopted the reduced 8-item FLCAS as a tool to measure EFL learners' FL anxiety in classroom settings. It is a standard 5-point Likert scale ranging from "strongly disagree" to "strong agree". After replacing the term "FL" in the original scale with "English", all the items were translated into Chinese by the author referring to the previous research. The translation was then checked by an experienced Chinese-English bilingual teacher and a consensus was reached after discussing the discrepancies. A scale analysis indicated a very high internal consistency (Cronbach's alpha $=.801, n=$ $15)$. 
b. Foreign Language Enjoyment Scale (revised Chinese version)

This study used the Chinese version of Foreign Language Enjoyment Scale (CFLES) developed by Li, Jiang, and Dewaele (2018). 11 positively phrased items were extracted from the original 21-item Foreign Language Enjoyment Scale (FLE Scale) developed by Dewaele and MacIntyre (2014). The modified 11-item Chinese version scale is a 5-point Likert scale, covering three factors of FLE: private, teacher and atmosphere (Li, Jiang, \& Dewaele, 2018). It has been tested to be an effective tool to measure learners' FLE in a Chinese EFL context. In this study, the internal consistency of the scale was good (Cronbach's alpha $=.805, n=15$ ).

\section{Open-Ended Questions}

The open-ended questions employed in this study were composed of two items: "1. Please describe a learning experience that you really enjoyed in a college English course. Give as much detail as possible about the situation and your feelings at that time; 2. Please describe a learning experience that you really felt anxious in a college English course. Give as much detail as possible about the situation and your feelings at that time." The questions were in Chinese to ensure that the participants can understand the questions accurately and express their opinions freely and clearly.

\section{Data Collection}

There were two stages for data collection. In the first stage, the researchers distributed the composite questionnaire to the participants in the four classes after class. The research purposes of the study were only partially disclosed before distributing questionnaires to avoid participants giving answers based on their anticipations of the researcher's inclination. It was collected in a traditional paper-and-pencil way. Students were guaranteed to participate voluntarily and anonymously. A total of 240 copies of questionnaires were distributed and 236 were returned with a response rate of 98.3\%. 5 copies of questionnaires with incomplete information were abandoned. Therefore, there were 231 cases left in the database. Data collection in the second stage was carried out one week later. 60 students were randomly selected from the four classes to participate in the open-ended questionnaire survey on a voluntary and anonymous basis. After checking the 58 questionnaires returned, it was found that 54 participants $(90 \%)$ gave answers to the episode of enjoyment, and 55 participants $(91.7 \%)$ to anxiety.

\section{Data Analyses}

Quantitative data were analyzed with the SPSS statistical software. First, 231 composite questionnaires were coded with the following way: "strongly agree" $=5$, "agree" = 4, "neither agree nor disagree" = 3, "disagree" = 2, "strongly disagree" $=1$. Among all 19 items, item 4 and 5 which suggest low anxiety were reverse-coded. Therefore, in this study, a higher score indicated a higher level of anxiety or enjoyment. After all the questionnaire data were input into SPSS 19.0, one-sample Kolmogorov-Smirnov tests were conducted to examine the distribution of data. Results showed that both FLE $(K S=0.978, P=.294)$ and FLCA $(K S=1.211, P=.106)$ followed the normal distribution. Therefore, this study opted for parametric statistics.

Qualitative data collected from two open-ended questions were entered into Word document. With the help of NVivo 11.0, the data were coded and node statistics were performed. In order to ensure the consistency and effectiveness of the coding, the author and another English teacher with research experience first coded the writing fragments independently. Afterwards the two parties checked the inconsistent codes and discussed them until a consensus was reached.

\section{RESULTS}

\section{A. Levels of FLE and FLCA}

In response to Research Question 1, descriptive analyses and normality tests were conducted with SPSS 19.0. As presented in Table 2, both the mean scores of FLE (36.22) and FLCA (27.16) of the participants were in the middle area of the score segment (33-44, 24-32), indicating that the participants of this study had moderate levels of FLE and FLCA (slightly higher than the critical value). Besides, the mode and median in Table 2 reflected the overall characteristics of the two emotions of the research subjects, while the standard deviation, maximum and minimum were reflections of individual differences.

TABLE II

DESCRIPTIVE ANALYSES AND NORMALITY TESTS OF FLE AND FLCA $(N=231)$

\begin{tabular}{llllllllll}
\hline & Possible range & Mean $(S E)$ & $S D$ & Min & Max & Mode & Median & Skewness $(S E)$ & Kurtosis $(S E)$ \\
\hline FLE & $11-55$ & $36.22(.30)$ & 4.61 & 21 & 51 & 34 & 36.19 & $.06(.16)$ & $.81(.32)$ \\
FLCA & $8-40$ & $27.16(.34)$ & 5.17 & 11 & 40 & 29 & 28.00 & $-.25(.16)$ & $.27(.32)$ \\
\hline
\end{tabular}

After calculation, the average FLE was $3.29(S D=.42)$ and average FLCA was $3.40(S D=.65)$. A paired $t$-test revealed that there was no significant difference between the level of FLE and FLCA $(d f=230, t=-1.906, p$ $=.058>.05)$.

\section{B. Gender Differences in FLE and FLCA}


Independent $t$-tests found that gender difference was not significant in FLE $(d f=229, t=-.709, p=.479>.05)$ $($ Females FLE $=3.27, S D=.37$; Males FLE $=3.31, S D=.47)$, but it was significant in FLCA $(d f=229, t=4.552, p$ $=.000<.001)$. Female learners' anxiety in English classes was much higher than that of their male counterparts $($ Females FLCA = 3.58, $S D=.63$; Males FLCA = 3.21, $S D=.61)$.

\section{Differences in FLE and FLCA between Intermediate and Low English Proficiency Groups}

In order to examine whether there were differences in FLE and FLCA between the intermediate level group (Class A and B) and low level group (Class C and D), independent $t$-tests were performed. The results revealed that there were no significant differences for either FLE or FLCA between intermediate and low English proficiency groups (see Table 3).

TABLE III

DESCRIPTIVE ANALYSES AND INDEPENDENT T-TESTS OF FLE AND FLCA

\begin{tabular}{llllllll}
\hline & Group & $N$ & Mean & $S D$ & $t$ & $p$ & $d f$ \\
\hline \multirow{2}{*}{ FLE } & Intermediate level & 120 & 3.26 & .42 & \multirow{2}{*}{-1.113} & .267 & 229 \\
& Low level & 111 & 3.32 & .42 & & & \\
\multirow{2}{*}{ FLCA } & Intermediate level & 120 & 3.44 & .63 & \multirow{2}{*}{1.167} & .244 & 229 \\
& Low level & 111 & 3.34 & .66 & & \\
\hline
\end{tabular}

\section{Sources of FLE and FLCA of Learners with Intermediate and Low English Proficiency}

Learners' emotional experience in FL classrooms collected through open questions was complex and diverse. After carefully reading and combing the content of the collected writing fragments, the sources of FL learners' FLE and FLCA were mainly classified into three categories: self, teacher and peer. Since many fragments covered multiple topics and contained different types of sources of emotion, repeated coding was used when coding writing fragments. The results of data coding and node statistics of the writing fragments were shown in Table 4 and Table 5.

TABLE IV

STATISTICS OF SOURCES AND FREQUENCIES OF FLE

\begin{tabular}{llll}
\hline Category & Self & Teacher & Peer \\
\hline Sources (frequency) & Excellent classroom performance & Classroom activities (31) & Peer interaction (6) \\
& $(4)$ & Teacher support and approval (7) & Peer support (1) \\
& Making progress (3) & Teaching contents (7) & \\
& Feeling of freshness (3) & Classroom atmosphere created by & \\
& Successful self-challenge (2) & teacher (7) & \\
& Sense of fun (1) & Teacher skills (5) & $7(8.5 \%)$ \\
& Other (3) & Teacher personality (2) & \\
\hline
\end{tabular}

As shown in Table 4, 54 learners with intermediate and low English proficiency reported a total of 82 writing fragments (including repetitive coding fragments) of FLE. The most mentioned was teacher factors (72\%), followed by self factors (19.5\%) and peer factors (8.5\%).

Teacher-related sources of FLE reported by participants in this study can be classified into 6 categories: classroom activities (e.g., group discussion, role play), teacher support and approval (e.g., praise, reward), teaching contents (e.g., daily topic, anecdote), classroom atmosphere created by teacher (e.g., relaxed, active atmosphere), teacher skills (e.g., teaching method, classroom organization and management) and teacher personality (e.g., humorous, easy-going). Among them, classroom activities were mentioned the most times. According to students' feedback, FL classroom activities in novel and interesting styles can stimulate their interest in learning, enliven classroom atmosphere, and boost enjoyment. Many students described the gains and enjoyable experience brought by a certain classroom activity, for example, as $\mathrm{S} 48^{1}$ experienced:

During an English class, we learned a text about spatial sequence. The teacher asked several students in each group to present the content of the text in pictures on blackboard. Each student had a different understanding and drawing style. The atmosphere in the classroom was very active and my understanding of the text was also deepened." (male, 19 years old)

As for self-factors, students usually feel happy because of their outstanding performance or progress achieved by self-effort, as a male learner (S1, 20 years old) explained: "I memorized the new words carefully after class. When dictating, I got the highest score in the class, and the teacher said she would add me extra points as a reward." Besides, the feelings of freshness can bring FL learners joyful learning experience:

I enjoyed the viewing part of the listening class the most. Although the videos played didn't have subtitles, I can watch many interesting things. What impressed me most is a video clip about a man traveling to an African tribe. What he saw and heard there was very interesting to me. (S36, female, 19 years old)

Peer interaction was mentioned six times as a main category of peer factors evoking enjoyment in FL classroom. Peer

\footnotetext{
1 Anonymous survey was adopted in this qualitative study. The letter "S" refers to "student" and the number represents participant's number.
} 
interaction can enhance the relationship between students and make the learning atmosphere more harmonious. One participant described in detail the process and feelings of interacting and communicating with peers:

When dividing study groups in English class, the teacher asked each of us to take a picture out of a box. Then the students having the same picture formed a group. Group members would work out a presentation together. Other groups would ask questions after the presentation. It might be a little embarrassing to meet other students and communicate with each other during this process, but we still felt very enjoyable. (S16, female, 19 years old)

TABLE V

STATISTICS OF SOURCES AND FREQUENCIES OF FLCA

\begin{tabular}{llll}
\hline Category & Self & Teacher & Peer \\
\hline Sources (frequency) & Failed to finish task (14) & Teacher questioning (9) & Peer nonsupport (2) \\
& Speaking without (adequate) & Classroom activities (5) & Peer pressure (2) \\
& preparation (13) & Teaching methods (4) & \\
& Poor English language proficiency & Ways of achievement \\
& evaluation (4) & & \\
& Bad classroom performance (9) & Teaching contents (1) & \\
& Examinations or quizzes (6) & & \\
& Fear of failure (5) & & \\
& Speaking in public (3) & & \\
& Other (4) & $23(25.6 \%)$ & \\
\hline
\end{tabular}

Different from the sources of enjoyment, in 90 writing fragments involving anxiety, the most mentioned by respondents was self factors (70\%), followed by teacher factors (25.6\%) and peer factors (4.4\%) (see Table 5). According to feedback from participants, a lot of anxiety in FL classroom was largely due to their own reasons. Among them, anxiety caused by not completing the learning task is the most common. One of the participants remembered the worry and guilt that arose when he forgot to do his homework and encountered the teacher's random check:

Once I forgot to finish my homework, I was very anxious when the teacher carried a random check. I was worried that I would give a bad impression on the teacher and I might get a low grade. I was also afraid of not being able to keep up with the teacher's pace when reviewing the exercises in class. I really felt guilty at that time. (S37, male, 21 years old)

In addition, unprepared or insufficiently prepared speeches were also a main source of anxiety in FL classroom repeatedly mentioned by learners.

Compared with self factors, anxiety caused by teacher factors wasn't mentioned too much by participants. Among the category of teacher factors, teacher questioning was mentioned most frequently. Some students described the feelings of being asked in class and the self-doubt and frustration after answering a question:

I often feel anxious and flustered when English teacher was naming someone to answer questions. Even if I was well prepared, I still felt flustered, nervous and uneasy, especially when looking at the teacher. I remember one time after answering a question in class, I guessed that my performance was not good and I won't get a high score this time. My English is so poor. It must be difficult to pass the final exam. I felt really depressed on thinking of that. (S47, female, 19 years old)

With regard to peer factors, some learners mentioned the anxiety and discouragement caused by peer pressure: "There was a period of time when everyone was preparing for College English Test in class. Looking at students around me who were working hard on it, I felt quite anxious. I thought I couldn't make it. My English was so poor." (S30, male, 19 years old)

\section{DISCUSSION}

The first research question focused on levels of FLE and FLCA of Chinese EFL learners with intermediate and low English proficiency. Participants reported moderate levels of FLE and FLCA with no significant difference between these two variables. Compared with the findings of Dewaele and MacIntyre's (2014) investigation of 1746 FL learners around the world, the mean level of FLE in the present study $(M=3.29)$ was much lower than that of the international sample $(M=3.82)$, but FLCA $(M=3.40)$ was much higher than the mean FLCA level reported in their study $(M=2.75)$. This further confirms that Asian FL learners have high anxiety and low enjoyment in FL learning (Dewaele \& MacIntyre, 2014). Besides, the enjoyment level reported in this study was far below the mean FLE level of the Chinese EFL undergraduates $(M=3.94)$ in Jiang and Dewaele (2019), but anxiety level was higher than the domestic sample reported in their study $(M=3.14)$.

The low enjoyment presented by Chinese EFL learners with intermediate and low English proficiency might be attributed to the teaching methods, teaching contents and classroom atmosphere which cannot arouse learners' interests. This suggests that English teachers need to tailor instructional strategies to the needs of different learners for effective teaching. Students with low FL levels need more flexible and interesting ways to stimulate enthusiasm and classroom participation, and eventually increase enjoyment. As for the high anxiety presented by participants in this study, it might be related to the lack of self-discipline, learning autonomy, self-confidence as well as the fear of losing face. In addition, 
it might be also largely due to the stressful educational environment in higher education in China. At present, some Chinese colleges and universities still take passing the CET-4 (College English Test Band 4) as one of the conditions for granting degree certificates. Repeated failures and the increase of grade levels may cause a stronger sense of anxiety for intermediate and low English proficiency learners in classroom settings.

The second research question dealt with the gender differences in FLE and FLCA. While no significant gender differences were found in FLE, there were obvious differences in FLCA, with females' anxiety levels much higher than that of males. These results are only partially consistent with previous studies (Dewaele \& MacIntyre, 2014; Dewaele, MacIntyre, Boudreau, \& Dewaele, 2016; Dewaele, Witney, Saito, \& Dewaele, 2018; Jiang \& Dewaele, 2019). Some studies mentioned above revealed significant gender differences in both FLE and FLCA, with female respondents experiencing both higher FLE and FLCA than male respondents (Dewaele \& MacIntyre, 2014; Dewaele, MacIntyre, Boudreau, \& Dewaele, 2016; Dewaele, Witney, Saito, \& Dewaele, 2018). It was explained as more emotional involvement in FL learning by female learners, and they would experience more emotional ups and downs than male learners (Dewaele, Witney, Saito, \& Dewaele, 2018). On the contrary, Jiang and Dewaele (2019) found no gender differences in FLE and FLCA among Chinese EFL learners. One possible explanation for the inconsistent results is that it might be related to sample size, participants' FL levels, learning environment, cultural background and other FL-related factors. This also suggests that the gender effects on emotions in SLA still merit further exploration.

The third research question examined the differences in FLE and FLCA between intermediate and low English proficiency groups. Independent $t$-tests revealed that there were no significant differences for either FLE or FLCA between these two groups. This is partly consistent with the results of Dewaele, Witney, Saito, and Dewaele's study (2018) on learners' FLE and FLCA where low intermediate and intermediate learners were only found to have significant differences in FLE. This further confirms that the trend of an increase in enjoyment and decrease in anxiety is more likely to occur on learners above intermediate level (Dewaele \& MacIntyre, 2014).

The final research question focused on the sources of FLE and FLCA for Chinese EFL learners with intermediate and low English proficiency. The results of qualitative data analysis showed that there were obvious differences in the factors that affect learners' FLE and FLCA. In the current study, while teacher factors were the main source of enjoyment in FL classroom, it accounted for only a quarter of the anxiety experiences reported by participants. Consistent with existing research results (Dewaele \& MacIntyre, 2014; Jiang \& Dewaele, 2019; Jiang, 2020), classroom activities were found to be the most frequently mentioned source of enjoyment for FL learners. The findings also confirm that enjoyment is a positive emotion that can be easily provoked in teaching activities or tasks (Pekrun, 2006). It indicates that when FL learners participate in classroom activities that are interesting and controllable, their positive emotions are more likely to be aroused. In contrast, participants' reports revealed that most FLCA was caused by self factors. Failing to complete learning tasks or speaking without (adequate) preparation in class will greatly trigger the anxiety and panic of intermediate and low proficiency learners. The above findings of this study also corroborate the view that FLE is more related to teacher factors, while FLCA is more related to learners' self factors (Dewaele, Witney, Saito, \& Dewaele, 2018; Jiang \& Dewaele, 2019).

The present study was not without some limitations. First, the research sample was only from one Chinese university, which was limited in size and diversity. Hence, the findings of this study cannot be generalized to all intermediate and low proficiency Chinese EFL learners. Further research could expand the number and coverage of participants, gathering data from different regions or different levels of universities in China. Second, only self-report was used to collect participants' enjoyment and anxiety episodes. Future studies can combine it with other instruments such as classroom observations or in-depth interview so that the sources of FLE and FLCA can be explored more broadly.

\section{CONCLUSION}

This study has investigated the FLE and FLCA of intermediate and low proficiency Chinese EFL undergraduates. In general, moderate levels of FLE and FLCA were found among participants. However, the level of FLE reported in this study was much lower than the overall international and domestic samples, while the level of FLCA was the opposite. This further confirms that FL learners in Asia have high anxiety and low enjoyment in learning. No significant gender difference was found in FLE, but female learners reported much more FLCA than their male peers. Moreover, there were no significant differences in the levels of FLE and FLCA among intermediate and low proficiency group. Finally, qualitative data analysis revealed that respondents' FLE was related to teacher factors to a large extent, while FLCA was more related to self factors.

The findings of the current study have some pedagogical implications for EFL teaching and research in China. First, given to the important role of emotion in SLA, the low enjoyment and high anxiety presented by intermediate and low proficiency Chinese EFL learners deserves the attention and alertness from FL practitioner and scholars. Intervention strategies should be explored to improve the current situation. Second, although teacher factors are not the main source of students' anxiety in class, FL teachers should keep developing the self-control ability and learning habits of students with poor academic performance, give them adequate time to prepare for answers and create a friendly, enjoyable classroom environment. Thus it would be helpful for controlling learners' negative emotions in FL class and eventually achieving a balance between anxiety and enjoyment. Finally, schools are suggested to combine academic goals with happiness goals and promote Positive Education, enhancing students' positive emotional experience, and ultimately 
achieving the goal of improving learners' happiness, well-being as well as teaching effectiveness.

\section{APPENDIX CLASSROOM EMOTION QUESTIONNAIRE ITEMS}

\begin{tabular}{|c|c|c|}
\hline Item & Chinese & English \\
\hline 1 & 即使已经为英语课做好充分的准备, 我还会感到焦虑。 & $\begin{array}{l}\text { Even if I am well prepared for English class, I feel anxious } \\
\text { about it. }\end{array}$ \\
\hline 2 & 我总觉得其他同学的英语说得比我好。 & $\begin{array}{l}\text { I always feel that the other students speak English better } \\
\text { than I do. }\end{array}$ \\
\hline 3 & $\begin{array}{l}\text { 英语课上老师点到我的名字让我回答问题时, 我会感 } \\
\text { 觉到紧张。 }\end{array}$ & $\begin{array}{l}\text { I can feel my heart pounding when I'm going to be called } \\
\text { on in English class. }\end{array}$ \\
\hline 4 & 英语课上我不担心犯错误。 & I don't worry about making mistakes in English class. \\
\hline 5 & 英语课上, 我讲英语时感到自信。 & I feel confident when I speak English in English class. \\
\hline 6 & 当我在英语课上讲英语时我感到紧张和困惑。 & $\begin{array}{l}\text { I get nervous and confused when I am speaking in my } \\
\text { English class. }\end{array}$ \\
\hline 7 & $\begin{array}{l}\text { 英语课上, 在没有准备而又不得不发言的情况下, 我 } \\
\text { 开始恐慌。 }\end{array}$ & $\begin{array}{l}\text { I start to panic when I have to speak without preparation in } \\
\text { English class. }\end{array}$ \\
\hline 8 & 英语课上, 主动回答问题让我觉得笽䛈。 & $\begin{array}{l}\text { It embarrasses me to volunteer answers in my English } \\
\text { class. }\end{array}$ \\
\hline 9 & 我不厌倦英语学习。 & I don't get bored. \\
\hline 10 & 我享受英语学习。 & I enjoy it. \\
\hline 11 & 学英语的过程中, 我学了很多有趣的事情。 & I've learnt interesting things. \\
\hline 12 & 在班里，我为自己的英语成绩感到自豪。 & In class, I feel proud of my accomplishments. \\
\hline 13 & 周围英语学习的氛围很积极。 & It's a positive environment. \\
\hline 14 & 学英语很有趣。 & It's fun. \\
\hline 15 & 老师总是鼓励我们。 & The teacher is encouraging. \\
\hline 16 & 老师很友善。 & The teacher is friendly. \\
\hline 17 & 老师总是支持我们。 & The teacher is supportive. \\
\hline 18 & 我身边有很好的英语学习氛围。 & There is a good atmosphere. \\
\hline 19 & 我们有紧密的学习小组。 & We form a tight group. \\
\hline
\end{tabular}

\section{ACKNOWLEDGEMENTS}

This research was supported by the 2021 Young Scholars Cultivation Project of Hainan University (Grant No. 21XSGG7). The author would also like to thank all the participants for their collaboration in this study.

\section{REFERENCES}

[1] Aida, Y. (1994). Examination of Horwitz, Horwitz, and Cope's construct of foreign language anxiety: The case of students of Japanese. The Modern Language Journal, 78(2), 155-168.

[2] Bailey, K. M. (1983). Competitiveness and anxiety in adult second language learning: Looking at and through the diary studies. In H. W. Seliger \& M. H. Long (Eds.), Classroom oriented research in second language acquisition (pp. 67-102). Rowley, MA: Newbury House.

[3] Boudreau, C., MacIntyre, P. D., \& Dewaele, J.-M. (2018). Enjoyment and anxiety in second language communication: An idiodynamic approach. Studies in Second Language Learning and Teaching, 8(1), 149-170.

[4] Chastain, K. (1975). Affective and ability factors in second language acquisition. Language Learning, 25, 153-161.

[5] Chiang, Y. N. (2010). Foreign language anxiety and student interpreters' learning outcomes: Implications for the theory and measurement of interpretation learning anxiety. Meta, 55(3), 589-601.

[6] Cohen, Y., \& Norst, M. J. (1989). Fear, dependence and loss of self-esteem: Affective barriers in second language learning among adults. RELC Journal, 20 (2), 61-77.

[7] Dewaele, J.-M. (2002). Psychological and sociodemographic correlates of communicative anxiety in L2 and L3 production. International Journal of Bilingualism, 6, 23-38.

[8] Dewaele, J.-M., \& Alfawzan, M. (2018). Does the effect of enjoyment outweigh that of anxiety in foreign language performance? Studies in Second Language Learning and Teaching, 8(1), 21-45.

[9] Dewaele, J.-M., \& Li, C. (2018). Editorial: Special issue "Emotions in SLA". Studies in Second Language Learning and Teaching, 8(1), 15-20.

[10] Dewaele, J.-M., \& Li, C. (2020). Emotions in second language acquisition: A critical review and research agenda. Foreign Language World, 1, 34-49.

[11] Dewaele, J.-M., \& MacIntyre, P. D. (2014). The two faces of Janus? Anxiety and enjoyment in the foreign language classroom. Studies in Second Language Learning and Teaching, 4(2), 237-274.

[12] Dewaele, J.-M., \& MacIntyre, P. D. (2016). Foreign language enjoyment and foreign language classroom anxiety. The right and left feet of the language learner. In P. D. MacIntyre, T. Gregersen, \& S. Mercer (Eds.), Positive psychology in SLA (pp. 215-236). Bristol: Multilingual Matters.

[13] Dewaele, J.-M., MacIntyre, P. D., Boudreau, C., \& Dewaele, L. (2016). Do girls have all the fun? Anxiety and Enjoyment in the Foreign Language Classroom. Theory and Practice of Second Language Acquisition, 2(1), 41-63.

[14] Dewaele, J.-M., Witney, J., Saito, K., \& Dewaele, L. (2018). Foreign language enjoyment and anxiety: The effect of teacher 
and learner variables. Language Teaching Research, 22(6), 676-697.

[15] Elahi Shirvan, M., \& Taherian, T. (2018). Longitudinal examination of university students' foreign language enjoyment and foreign language classroom anxiety in the course of general English: Latent growth curve modeling. International Journal of Bilingual Education and Bilingualism. https://doi.org/10.1080/13670050.2018.1441804.

[16] Fredrickson, B. L. (2001). The role of positive emotions in positive psychology: The broaden-and-build theory of positive emotions. American Psychologist, 56(3), 218-226.

[17] Fredrickson, B. L. (2003). The value of positive emotions. American Scientist, 91(4), 330-335.

[18] Gregersen, T., \& Horwitz, E. K. (2002). Language learning and perfectionism: Anxious and non-anxious language learners' reactions to their own oral performance. The Modern Language Journal, 86(4), 562-570.

[19] Horwitz, E. K. (1986). Preliminary evidence for the reliability and validity of a foreign language anxiety scale. TESOL Quarterly, 20(3), 559-562.

[20] Horwitz, E. K. (2000). It ain't over 'til it's over: On foreign language anxiety, first language deficits, and the confounding of variables. The Modern Language Journal, 84(2), 256-259.

[21] Horwitz, E. K. (2010). Foreign and second language anxiety. Language Teaching, 43, 154-167.

[22] Horwitz, E. K., Horwitz, M. B., \& Cope, J. (1986). Foreign language classroom anxiety. The Modern Language Journal, 70(2), 125-132.

[23] Jiang, G., \& Li, C. (2017). SLA research in the Positive Psychology perspective: Review and prospects. Foreign Language World, 5, 32-39.

[24] Jiang Y. (2020). An investigation of the effect of teacher on Chinese university students' foreign language enjoyment. Foreign Language World, 1, 60-68.

[25] Jiang, Y., \& Dewaele, J.-M. (2019). How unique is the foreign language classroom enjoyment and anxiety of Chinese EFL learners? System, 82, 13-25.

[26] Jin, Y., \& Zhang, L. J. (2018). The dimensions of foreign language classroom enjoyment and their effect on foreign language achievement. International Journal of Bilingual Education and Bilingualism. https://doi.org/10/1080/13670050.2018.1526253.

[27] Krashen, S. D. (1982). Principles and practice in second language acquisition. Oxford: Pergamon Press.

[28] Krashen, S. D. (1985). The Input Hypothesis: Issues and Implications. Boston, MA: Addison-Wesley Longman Ltd.

[29] Li, C. (2020). Emotional intelligence and English achievement: The mediating effects of enjoyment, anxiety and burnout. Foreign Language World, 1, 69-78.

[30] Li, C., Dewaele, J.-M., \& Jiang, G. (2019). The complex relationship between classroom emotions and EFL achievement in China. Applied Linguistics Review. https://doi.org/10.1515/applirev-2018-0043.

[31] Li, C., Huang, J., \& Li, B. (2020). The predictive effects of classroom environment and trait emotional intelligence on Foreign Language Enjoyment and Anxiety. System. https://doi.org/10.1016/j.system.2020.102393.

[32] Li, C., Jiang, G., \& Dewaele, J.-M. (2018). Understanding Chinese high school students' Foreign Language Enjoyment: Validation of the Chinese version of the Foreign Language Enjoyment Scale. System, 76, 183-196.

[33] Liu, M., \& Jackson, J. (2008). An exploration of Chinese EFL learners' unwillingness to communicate and foreign language anxiety. The Modern Language Journal, 92(1), 71-86.

[34] MacIntyre, P. D., \& Gardner, R. C. (1994a). The subtle effects of language anxiety on cognitive processing in the second language. Language Learning, 44, 283-305.

[35] MacIntyre, P. D., \& Gardner, R. C. (1994b). The effects of induced anxiety on cognitive processing in computerised vocabulary learning. Studies in Second Language Acquisition, 16, 1-17.

[36] MacIntyre, P. D., \& Gregersen, T. (2012). Emotions that facilitate language learning: The positive-broadening power of the imagination. Studies in Second Language Learning and Teaching, 2(2), 193-213.

[37] MacIntyre, P. D., \& Mercer, S. (2014). Introducing positive psychology to SLA. Studies in Second Language Learning and Teaching, 4(2), 153-172.

[38] Pekrun, R. (2006). The control-value theory of achievement emotions: Assumptions, corollaries, and implications for educational research and practice. Educational Psychology Review, 18(4), 315-341.

[39] Piechurska-kuciel, E. (2011). Perceived teacher support and language anxiety in Polish secondary school EFL learners. Studies in Second Language Learning and Teaching, 1(1), 83-100.

[40] Scovel, T. (1978). The effect of affect on foreign language learning: A review of the anxiety research. Language Learning, 28, 129-142.

[41] Seligman, M. E. P. (2006). Afterword: Breaking the 65 Percent Barrier. In M. Csikszentmihalyi \& I. S. Csikszentmihalyi (Eds.), A life worth living: Contributions to positive psychology (pp. 230-236). New York: Oxford University Press.

[42] Seligman, M. E. P., \& Csikszentmihalyi, M. (2000). Positive psychology: An introduction. American Psychologist, 55(1), 5-14.

[43] Spielberger, C. D. (1983). State-trait anxiety inventory for adults. Menlo Park, CA: MindGarden.

Huina Su is a PhD student in Linguistics (English) at the University of Macau, China. She is also a lecturer at Hainan University, China. Her research interests include second language acquisition, English language teaching and learning. 